\title{
The Present as Future: The Problem of Translation in Corporate Science Projects
}

\author{
Eleanor Wynn \\ eleanorwynn3@gmail.com
}

\begin{abstract}
The paper reviews a set of research projects intended to plan for the future. It uses an actor-network construct from Latour's work on science practice, translation. The paper contrasts normal science practice with science in a corporate context. Both situations occur in actor networks, require translation and contain arbitrary decisions. The corporate context can be more problematic because of the greater diversity of actors and agendas. The longer the work goes on, the more actors there are. Research per se is a sustained effort toward emergent goals; in the context of fluid corporate networks, these goals can become lost in mis-translation from one phase to the next. Results that would otherwise build up science findings miss their mark, are delayed, or are overtaken by other developments. The findings exist, but the outcomes for which they were intended may not materialize.
\end{abstract}

Keywords: Corporate research, virtual teams, machine learning, desktop information management, 3D user interface, innovation.

"Is it our fault if the networks are simultaneously real, like nature, narrated, like discourse, and collective, like society?"(Latour 1993, p.6)

\section{Introduction}

Latour emphasizes the role of translation from one step of scientific process to another. The results are transportable abstractions that allow the original facts on the ground to be progressively formalized and encoded for dissemination. In Pandora's Hope, Latour follows this process through several chapters on the classification of soils from the Brazilian jungle-savannah boundary. The research question was whether the jungle or the savannah was advancing; the answer would be based on soil and plant types. The interdisciplinary team of scientists literally took dirt out of the ground, placed it into a grid of small boxes, and progressively abstracted its form from there, with iterations of process to ensure fidelity: that what came out the other end as "science" actually represented the categories and locations of dirt where it was found. He calls this process translation. At each step the content changes its substance but should be traceable back to the original substance due to fidelity of translation. Therefore, any generalizations made from the abstractions ought to be true of the 
original material. Latour (1993) includes and even privileges anthropology in the sciences; so this discussion does not engage the quantitative-qualitative distinction.

When science is carried out in a corporation, the translation process easily becomes distorted by other agendas. The context is normally science for the production of some good, either basic processes for products and inventions, or internal uses like manufacturing. More recently, workforce and end users have become subjects for examination. In this engagement, the researcher is likely a well qualified person trained in methods. This person will, therefore, have faithful translation as a basic unstated goal. The difference between corporate and academic science is done with the results. This can change with changing actors. So even though each step of the process may be science, the end-to-end process itself may not. The predilections of actors at a senior level and their long-range views are critical in this fidelity. Since these actors and agendas change, the corporation introduces more variability than our sense of science normally allows.

Actors in the network take the form of human players, management objectives, reward systems, technology capabilities, research methods, and externally sourced solutions, to name a few. The translation lens helps us understand what should happen even in the fragile process of constructing academic science, and what the expectation of a research undertaking is. The violation of this principle explains obstacles in researching the future in a complex situation with a broad range of changing actors.

The present "case" is a series of research projects carried out over 8 years. The purpose of the projects was to guide IT decisions about key features of virtual collaboration tools for the company workforce. Collaboration tools were seen as problematic because the workforce had come to operate in an increasingly distributed fashion based on various policies. Each project led to a new question. A variety of methods came into play depending on the nature of the questions.

It is worth spending a moment to address the question of "problems" and their relationship to researching the future. A problem is a form of breakdown or anticipated breakdown (Dreyfus 1984; Zimmerman 1990). Even though a problem may be "experienced," its causes and details remain unanalyzed until it is reflected upon. The present tends to be taken for granted even when problems are experienced. The process of coping with problems was characterized in Hammer and Champy (2001) as "workarounds"; this characterization still applies. If the present is ready-to-hand (Dreyfus 1978) then why analyze it and why think of changes for the future? Workarounds can build up to a point where eventually they cause a breakdown. Then the present is experienced as problematic or present-at-hand, and leads to thoughts about a different future. This requires a different perspective on what is actually happening in the present.

The dilemma in an actor network is that what is the future to one actor may be the present to another. Failure to note this difference is part of the problem of translation. These problems are more likely to arise for end user and organizational research than in computer science and engineering because people already have perceptions and opinions about the former, but the latter are not exempt. Many innovations in software development have idled while stakeholders attempt to grasp the science, the usage model, or both. This series of projects contained software innovations that did not translate accurately to higher level actors, or ran into organizational problems like short-term agendas of individual human actors. The people working on a project see the project as fully present and even perhaps 
behind the current capabilities. Others who lack the same context may see it as so far into the future that it is not yet practical to execute. This becomes self-fulfilling.

Before researching the future, we must locate the future. Latour (1993) claims that it starts in a new understanding of the present. Innovative solutions rely upon insights about present problems or breakdowns and in most cases are paired with new technologies or methods for addressing them. Since the present is mostly ready-to-hand (Dreyfus 1978) and taken for granted, seeing and analyzing those problems is a challenge. Different stakeholders, therefore, see them differently or have different member analyses based on everyday reasoning.

Latour casts the reframing back into the past.

As soon as we direct our attention simultaneously to the work of purification and the work of hybridization, we immediately stop being wholly modern, and our future begins to change. At the same time we stop having been modern, because we become retrospectively aware that the two sets of practices have always already been at work in the historical period that is ending (Latour 1993, p. 11).

The future and the past are always part of the present. The calendar shows a difference between yesterday and tomorrow but trajectories of events are entangled with concurrent presents, pasts, and futures.

Just as a topic like global warming is concurrently political, scientific, and narrative, yet artificially divided (Latour 1993), the topic also contains within it different time horizons. Past events led to the present, current events affect the future, and, within any given moment, people are acting out different pasts, presents, and possible futures according to their position in a network, a perspective they are committed to, or how they are affected. Escobar (1995) refers to this as hybrid cultures where national and regional cultures include traditional and contemporary stances. Floods in Pakistan and drying mountain lakes in the Andes are the present for local people, but to people far away, they represent only a possible and tentative future. The researcher is often in a position of having either imagined or seen the possible future as an imminent reality, and then must convey or translate that to others for whom some other scenario occupies the overwhelming present and immediate future. A researcher of informatics in particular is always bridging present and future.

\section{Structure}

The paper has four major parts: (1) a discussion of researching the future; (2) applicable constructs; (3) thumbnails and rationales for a series of research projects; and (4) a discussion of where things went off track. All the projects together make the case. The case is a process of (1) becoming aware of questions in the environment; (2) efforts to answer those questions with research projects; (3) the sequence of new questions that arose with each project; (4) what happened to those results. The storyline loses momentum at the end because this is what happened to the research series even though the underlying need remains. We use Latour's (1999) translation construct in two ways: (1) faithful translation applied in science to get from an untransportable materiality into 
what counts as science results; (2) varying translations from the work into a corporate context as management changes occur.

The corporation needs the science work in order to move ahead with stated agendas, but can't always use it because of failures in the translation process. The motivation to develop a future ICT normally arises from a problem experienced in the present. The present is, therefore, the starting point for researching the future; however, it turns out that there are many different "presents" in play. Discrepancies in what constitutes the present are part of the problem of translation because of the gap in common perspective on what is futuristic and what is simply the next logical step. Researching the future becomes a sociology of knowledge; so we have also in mind if not in focus the work of Foucault (1972) and of Knorr-Cetina (1999).

\section{The Case (A Set of Projects)}

Zimmerman (1990) describes Heidegger's concern for the technological mindset where technology is seen as dominating, segmenting, and imposing instead of "uncovering." In this set of studies we adopted the latter, less deterministic process. We uncovered new problems in the search for answers to other questions. Unlike a conventional plan of research, we chose new methods opportunistically as questions (how virtual are we?), new facts or factants (most employees work on multiple teams), translation devices (demo), technical elements (an existing software solution), and methods (machine learning) emerged.

The goal of the projects was to provide better tools for collaboration, and to address discovered problems of multiple team memberships, multitasking and cognitive flow. The paper presents a summary of the research efforts and the emergent nature of discovery as each new finding gives rise to a new question. The collection of projects uses different methods over time to discover collaboration obstacles of a globally distributed workforce and potential software tools.

The actor-network construct and the notion of translations helps to explain the divergent outcomes of this research and related development efforts. It shows how research in a corporate environment differs from research in science because the translation mechanisms are damaged or under different pressures. Fidelity of translation is overtaken by other priorities.

The effort came from an IT organization because of IT's role in supplying workforce software tools. At the start of this work, the company had over 80,000 employees worldwide, functionally distributed with substantial proportions collaborating across the globe. This means that a single department had members in different parts of the globe and many of those members were on teams that regularly met periodically. Functional distribution is a strength in terms of creating communication channels and robust social networks across the company, but it poses a technological challenge to support information sharing and productive interaction.

Since we are looking at both the process of discovery and the issues of translation from an actor network perspective, below is an outline of the main actors.

- a core set of human actors interacting over time

- disciplinary backgrounds of the human actors 
- agendas arising from the backgrounds

- agendas arising from success criteria for individuals

- software tools for discovery and for development into user interface designs

- other research methods such as survey, interview and machine tracking

- factants or things discovered in the research

- present and future capabilities of software tools

- attraction factors of research findings and software tools

- organizational agendas that supercede the individual human actors and constrain them

- variation over time in all of these

\section{The Research Projects}

In this section, we review the projects. Each project arose to answer one or more questions and some questions arose from previous results.

The first question was the generalizability of the work practices of a team organized to define the problems and recommend a solution to the virtual collaboration needs of the company. In his writings on theorizing, sociologist Alan Blum (1974) points out that theory arises from everyday experience, but takes this as present-athand and thus seeks to form an analysis. The group described below engaged in theorizing about the nature of globally distributed teams and their needs. It then became important to test the informal hypotheses that were recurrently expressed as assumptions in the conversation. The expression "we're so virtual" led to a question as to what proportion of employees actually collaborated in ways similar to the team members.

The method for this question was a demographic survey. The second question arose from the challenge of how to represent the implications of the survey results so that more senior management could grasp them. This led to a video mock-up of a proposed design and included a three-dimensional representation of the desktop with interlinked personal and team workspaces. The third question arose from a specific result of the survey, that two-thirds of the workforce were members of many teams (three to five and more). This led to a series of machine learning studies to understand how people managed the information flow from these teams.

The research questions did not come directly from management stakeholders. Senior management created umbrella agendas leading to self-directed work. In most cases, the questions became evident from observed gaps in knowledge. The projects were carried out with normal scholarly process, where the assumed eventual audience would be peers in the academic community. Validity was assumed adequate within the internal audience, and at times the results were widely used by others. At other times, finer points were lost, or the research could not be processed as relevant due to translation gaps.

\subsection{The Virtual Collaboration Research Team}

A cross-functional team was organized by two senior individual contributors. Members included a workplace anthropologist, a product planner, two engineers, a software 
trainer, a collaboration product manager, and an engineering manager. Membership was by invitation and voluntary. The topic had a high profile on a vision/mission roadmap for IT. The company had experienced a period of expanded overseas growth and was functionally distributed. This means that all of the service organizations (information technology, finance, human resources) were globally distributed; most of the core product design teams were organized by geographic specializations around the globe but had to periodically coordinate design sections; manufacturing is site-focused but shared best practices and expertise and is highly standardized methodologically; and software development is often sourced from offshore; sales is highly distributed and typically standalone by region. Each division has different proportions and periodicity of distributed collaboration, but all have it.

\subsection{Virtuality Survey}

As the VCRT talked about global team collaboration, members periodically exclaimed "we're so virtual!" meaning that the company operates extensively in a "virtual" collaboration mode. But who are "we" and what is "virtual"? What does "we're so virtual" mean? It meant different things to different people. It had many confounded constructs embedded in it. To provide definition, extent, and impact of the different elements of virtual collaboration, we took the starting point of theorizing about our own behavior and undertook a survey to see how much of the workforce had the same experience.

A literature review paper (Watson-Manheim et al. 2002) had identified five factors in common within the IS literature on the use of the term virtual to describe corporations. In consultation with the authors, we defined a survey that would measure a composite index of virtuality along the dimensions of discontinuities in time, geography, culture, business unit, and software tools. We added the discontinuity of multiteaming because we noted that software products often contained assumptions of single team membership (Chudoba et al. 2005). This demographic survey was conducted using a stratified random sample of all employees in all job types and all geographies (Lu et al. 2003).These results provided a reliable measure of how virtual the company was and which dimensions made a difference. There was a high level of virtuality, with approximately two-thirds of employees being engaged in a virtual team and working across more than one of the discontinuities. The job profiles of people engaged in virtual teaming closely matched the job types within the company. Given these proportions, we could say that virtual teaming was a way of life and obstacles to it would be barriers to everyday productivity. (In a translation not discussed in the paper, the leap from these results to a finance-recognized metric did not materialize).

The survey included a measure of performance that could work across the wide array of job types and regions: the shared company values. These values represented common knowledge that could provide a reliable self-assessment of team performance. This metric held up well over the 7 years the survey was conducted in terms of consistency of response and ability to track a trend. We correlated the virtuality variables with the performance variables to determine the aggravating factors in virtual teaming. These turned out to be consistency of software tools, confirming that this 
was a problem within the scope of IT. Geography was a factor only when time separation was added, even though geography had been the most visible dimension of virtuality to decision makers. Within the United States, geographic location was neutral to team performance.

The survey thus disconfirmed the supposed negative effects of location along a North-South axis. East-West axis adds the dimension of time separation and a separate study was conducted on that (Cummings et al. 2009). Social variables like trust and friendship were the highest rated performance metrics for teams. This could be because virtual teaming was routine and made use of telephone bridges rather than conference rooms. This places everyone on an equally remote status. Incremental improvements in both internal and vendor supplied software over time smoothed out many hitches in coordination of meeting logistics. One likely organizational effect of virtual teaming was the tendency for people to participate in multiple (three to five) projects as location becomes a neutral factor.

The survey became an actor as the creator of factants that established the need for collaboration solutions and identified the types of need. It led to the development of a collaboration scenario that included multi-teaming as a core way of working and added the requirement for both separation of spaces on a display with coordination of content that might be shared across teams. That scenario was expressed in a mock-up that incorporated features of a technically sophisticated user interface that had been abandoned by the company product research labs before the IT collaboration effort began. The existence of this elegant technology became an actor and a pawn in the trajectory of events.

\subsection{The Demo}

The mock-up was an essential boundary object for translating the intentions the team developed into actions that could be taken by the organization. Many slide presentations were drafted and used for interim presentations; but without a visual display of what the solution would look like and act like, conversations with others elicited comparisons to standalone features of existing software tools. To the team members, those tools were incomplete because they lacked several things: the ability to address multiple team membership, location and cultural references for context, and the integration of core design features. Since key problems identified had been "too many tools" and "different tools," the solution of assembling yet another suite of off-theshelf products was antithetical to providing coordination.

The mock-up performed the role of translation device. At the same time it introduced a new functional element: 3D. This technology had its own history; it became the platform for engaging new actors, securing new funding, and acquiring a higher level of visibility. While these developments at the time seemed highly positive, they eventually led the translation process off track. While the demo communicated well as a simple mock-up, once the more sophisticated technology of the 3D source metaphor became funded, some of its technical virtuosity distracted from the original intent. The narrative of the survey data became a backdrop to why the 3D solution was desirable and together these made a great story and presentation. If they had remained together as rationales, the translation process would have continued along a normal scientific path as Latour describes it. 


\subsection{D User Interface for Information Management}

Once 3D was introduced as the graphic metaphor for the mock-up, it became obvious that it also contained a solution to one of the key problems encountered in the survey: the fact that two-thirds of employees work on three to five teams at any given point in time. With 3D as the user interface, users could keep all of their teams in mind (termed "all my teams in one place") as they toggled back and forth. This would solve the problem of multiple open and minimized windows that by the 2000 s made the virtual desktop no different than a physical desktop with piles of paper on it. The system that inspired the metaphor for the mock-up had the following history and properties.

In the late 1990s, a small group of lab researchers worked on software developments in sense-making. The goal was to break out of file structures to more intuitive ways of organizing and finding information and associated objects. The solution involved the development of a three-dimensional graphical space as the desktop context, whereby documents and other screen objects could be pushed to the "back," retaining their dimensions and appearance but becoming much smaller. The software was intended to incorporate object properties and drag-and-drop links between visual objects (documents, programs, and people) that would then retain their associations. Since it did not depend on file hierarchy, any object could be related to as many other objects as necessary. The purpose was to create a contextual order that was independent of file structure and more naturally followed human associative reasoning. This group was disbanded in 2001 during a reorganization and the software development discontinued. Some of the work that had gone into navigation, zooming, snapin-place, and 3D rendering and linking was truly pioneering and remains technically impressive (Light and Miller 2002).

This software informed the mock-up that was presented to IT staff at a strategic long range planning meeting. The sponsor who was present at the meeting told the team that the demo had "moved the cause of collaboration ahead by five years in the space of five minutes." There was a great deal of expressed excitement; a lab and group were funded to pursue this and other advanced collaboration solutions including video conferencing. The group had about 10 members, significant for an exploratory group in IT. The group hired one of the original 3D developers and a number of application scenarios were populated to illustrate how this solution would work in different parts of the company. This went along well for a few years until a companywide reorganization affected the entire department.

\subsection{Multi-teaming and Multitasking}

Consistent with the thesis that each new discovery leads to another question, we took the opportunity to work with faculty and students in the Department of Electrical Engineering and Computer Science at Oregon State University to try to understand the effects of multi-teaming and multitasking using two software programs developed at the Center for Machine Learning.

What the 3D software lacked at the time it was originally developed was a compelling usage scenario, which we might call another actor in the system. Although it looked good and the developers passionately believed it solved a problem of information management, 
no such problem had been credibly documented, either for the individual user or for sets of users working on multiple teams. The virtuality survey uncovered the structural situation that provided a strong rationale for the use of 3D. Although any given person might be aware of having to work across multiple teams, heretofore nobody had any notion of the extent of this company-wide. Even once it was known it was difficult to say exactly why it was a problem. Eventually the machine learning study revealed the kind of hyperactivity that this widespread and even organizationally functional behavior produced, and uncovered further problems hidden in everyday behavior.

Here several actors/agendas converged: the findings from the survey, the availability of the machine learning project, the ability to fund external research, and the 3D desktop design. The fact that the design was a technical artifact gave it added influence. It helped significantly that it was visually engrossing.

The Oregon State University projects used two different machine learning programs to instrument people's desktops for extended periods. No content was recorded for reasons of information security and end-user privacy. The software tracked a range of activities within the primary office application suite. Between the two programs, the software tracked window and applications switches, interruptions, and operations like cut/paste, file save/save-as, attach, open, etc. (Jensen et al. 2010).

The original pilot with TaskTracer (Stumpf et al. 2009) was meant to create project-based context retention by labeling and then storing together related documents so that they would all be visibly associated and therefore linked together regardless of file structure. This would address one of the issues revealed in the survey: if you are working on multiple teams using various collaboration software programs, how do you track what you are doing with each team? The file hierarchy is not quite adequate since many documents can be used across teams. With a traditional file hierarchy and even with shared storage, a version control problem immediately presents itself.

The first machine learning program, TaskTracer, required human mediation in order to "learn" meaningful associations. Results showed how much window and taskswitching was going on, but users quickly tired of trying to train the program. The practical goal of associating content was not realized. There were already so many categories to sort into and so much new information arriving hourly, mostly via email, containing project content (Bellotti et al. 2003) that it became overwhelming to establish the basic sorting framework for the program.

The hyperactivity traced with the program (window switches more than once a minute, 90 percent of file searches repeated in a session, etc.) arises from a scenario like a user participating in a phone bridge, concurrently looking at a document on a shared screen, answering e-mails, looking up information to answer the e-mails, and looking up other information pertinent to the meeting-all in the course of a half-hour. These behaviors are part of the pressures of work and the capability of instant information access and response. It becomes central to a real-time multi-tasking life-world that is efficient in many ways even while it has high cognitive costs.

\subsection{Cross-Application Information Flow and Provenance}

We funded the research to understand what users were doing on the client. Switching can be a benefit. The windows capability replaced modal computing in the 1980s and was considered an advantage (Tesler 1981). But the amount of switching driven by 
new models of work without the underlying software model keeping up has become frenetic. A new concept of information management is therefore critical. Because TaskTracer had a high adoption hurdle even as an experiment, we continued with a passive software program, TaskTrail, that solved a different problem, did not require user intervention, and applied pattern-matching after the fact rather than in real time.

TaskTrail tracked operations like opening and closing windows, switching windows, copy/paste, file save/save-as, file attach, and more to find out where information comes from. The work falls into the domain of provenance studies and was the largest such study to date. More than 20 users were tracked over a 2-month period, with initial and halfway interviews to provide the context of practice: "what were you trying to do?" The program, again recording no content, ran in the background. Computer Science/HCI graduate students at Oregon State University performed post hoc analysis. These data revealed patterns of information flow on the desktop and highlighted a user focus on information as contrasted with a vendor and IT emphasis on applications. The results show a long information half-life and heavy reuse patterns as users recontextualize and refine information objects available from various sources.

Significant percentages of information on a given user's desktop were copied from one document and/or application to another. This showed users create original documents by reusing large amounts of information from themselves and from others. They continually recontextualize information they have saved on the client, received in an attachment, or downloaded from a shared file or the Internet. These findings strongly support the informatization construct (Zuboff 1984). Each person recreates information relevance in light of a new context. But they are doing this through a maze of operations inconsistent with the model of use. We contend that software tools can make it much easier to coordinate and manage information through the visual interface.

\section{Outcomes}

The findings of the machine learning studies created more urgency for the use of the $3 \mathrm{D}$ environment to manage information, even as the latter motivated the machine learning studies. Supporting external research on hedonic and flow concepts (Reeves and Nass 2002) was brought in to justify 3D. Managers had resisted the notion that work should be like play, but the work on heart rate in first-person shooter videogames and on the effect of visual imagery on neurological flow states (Csikszentmihalyi 1997) were factants that became part of the internal marketing message for the 3D program. Although these findings were consistent with the trajectory of translations, they also led to a divergent path.

The research results could have had an impact on how IT influenced major vendors of office software. But new translation problems arose. The obviousness of the finding that people are focused on information, while vendors focus on applications, was not obvious to the engineering managers who implement new tools. Further, the research findings were overwhelmed by the sudden currency of the hedonic constructs: "work as play" and 3D visualization. Previously rejected in IT, these notions were reintroduced from another quarter at a higher level. The machine learning project ought to 
have supported an agenda of maximizing cognitive flow, which is the same neurological state for both productive and hedonic purposes. 3D is one way of doing that in the context of multi-teaming and the software was deemed technically first class.

But its technical brilliance and visual appeal gave the 3D piece of the network a life of its own. There had been a circularity of reinforcement. Once the virtuality survey findings justified the 3D user interface, that interface then justified further study of problems on the desktop arising from multi-teaming. This led the research trajectory back in the direction of the original intent of the 3D software effort from the 1990s, even though for a while the software was merely an accessory to illustrate some intentions about collaboration. Having the software and an original developer gave momentum to the 3D effort (along with the lab funding). Then it created a compelling reason to understand more about user behavior than could be provided in the survey or, for that matter, by any other means. This led to the machine learning work and could have led to new information management models.

Instead, shorter-term agendas requiring less faithful translation arose. A senior executive urgently needed materials for a keynote speech on the topic of "play." The 3D UI and its arguments were ready for that. Then the adrenaline of being on a senior management radar narrowed down the scope of participants and voices. Points that distract from the focus of an executive presentation, while essential, may seem like clutter. Once the senior manager was engaged, other managers were encouraged to push the play agenda farther. The 3D UI was now sufficiently developed to launch a joint venture with a company that was creating a virtual collaboration environment in the image of a game.

At this point, translation in Latour's sense became completely lost in other agendas and we switch over to a Foucauldian scenario. Play turned into "game" and game turned into "virtual environment with avatars and realistic rooms." The intellectual underpinnings of the agenda lost out to the shiny parts. In the end, the keynote was short-lived and did not lead to funding; a joint development project with another large company to use this software in an ambitious way fell apart due to decisions at their end; the third-party venture with the small company eventually fizzled (for lack of a compelling usage model). After large-scale organizational changes, the remaining core developer has seen the tide go out on an innovative idea for a second time and is seeking new funding.

It can always come back again once the future catches up to the past. There are organizational data, a usage model based on those data, constructs of cognitive flow, and task switching that have been measured. The research flow still adds up. And the world still needs this solution. All of this, both research and development, and the inspiration that guided them, became enmeshed in other agendas.

\section{Analysis: The Translations and Trajectories}

A network is both contemporary and historical. There were networks interacting across all of the projects discussed here to greater and lesser degrees. At any point in time, one or another actor had motivations and rewards in carrying the projects forward. Without a historically extended network, there never would have been a cohesive vision since there were temporal gaps in execution. Each person had different skills and levels of investment in the concepts and prototypes. One person was an 
original developer on the team that created the Labs version. Another focused on collaboration design options, workforce distribution data, and had a spatial (next cube) connection to a different original 3D developer. A third person was contracted to do a visual scheme for a concept presentation and remembered working on the 3D application. Others became persuaded of the 3D option. The availability of the machine learning research agenda led to supporting evidence that no survey or ethnographic method could have captured. The cognitive research on flow supported the general direction and created a back argument against the notion that work and play are two different things. Many translation processes here added up in a reasonable way. The agenda that cross cuts the translation is the need and urge to move the work up to a higher level of visibility and sponsorship. It is a need but it translates differently. The translation became as follows:

Questions about collaboration and the generalizability of team experience led to virtual team demographics. This led to the discovery of approximately two-thirds virtual teaming and the newly identified phenomenon of multi-teaming, which in turn identified shortcomings in software offerings. (Team repositories were created as standalone entities. If a user was on several teams, related documents had to be separately uploaded and version control was lost). This led to the need to translate into a compelling management message to gain funding, which took the form of the demo. The demo borrowed the 3D concept from an earlier abandoned project. The 3D software brought its own question: Just how bad is the information management problem? This gave rise to the machine learning projects. These had two roles, one of them just to understand information management on the desktop and the other to validate a compelling need for 3D as a solution. These things all had a logical sequence, even with the inclusion of the translation for management in the form of the demo.

The departure from translation came from the dynamics of a second round of translation for management. That first translation brought funding but no intervention. The second translation failed to carry along research justifications that went into the forward momentum of the whole effort. It turned 3D into show material and eventually lost its scientific and technological force.

In the rush of opportunity that surrounded the 3D development project as a potential commercial product, the chain of translation that Latour describes as working well in science through the care of human actors broke down. The most compelling representation can easily win out over the most faithful or most useful. The emphasis of the 3D desktop had shifted gradually away from information management: first to the service of a high quality public demo, and then to the allure of a product possibility involving a meeting space with sophisticated graphics. Because at each phase some of the actors and agendas changed, the information management concept dropped out of sight, even as the need for it was further emphasized by the machine learning research. Advocates for the information management usage model either were no longer in the conversation or were kept busy by technical challenges of navigation and visualization in the 3D space.

Instead of visual content management there were visual representations of spatial and physical objects that had game-like realism. Instead of an interface that provides a simplified window into something highly complex, the momentum went into something that was simple but fancy-looking. 


\section{Summary}

This case shows how the future had to be understood by making the present presentat-hand. This happened through a series of steps, each informed by the previous one, with new elements coming in opportunely. Research into the implications of the multi-teaming phenomenon revealed in the survey confirmed that this behavior introduces an information management and design challenge. A solution was readily available in the form of an abandoned software project that merited revival. However, due to the lack of translation and the power of certain inscriptions, the whole package of rationales failed to progress together.

The research remains as a finding about a possible future. This could serve as guidance for those who do science for any large institution. It is easy to be caught up in the seemingly intrinsic merits of an approach and findings, and to be unaware of power agendas and the need for two kinds of translation. One is translating not just through stages of science but up through a power hierarchy. Latour's philosophical resources provided the counterpoint of what makes science a method as a human process of faithful translation. The notion of translation, therefore, is precisely that element that can become lost when science is done for other audiences and with other actors. Much credit goes to Latour for his deep vision of anthropology and its capability as the science that pulls together the artificially sundered threads of past-present-future, science-nature-politics, and narrative.

\section{References}

Bellotti, V., Ducheneault, N., Howard, M., Smith, I.: Taking Email to Task: The Design and Evaluation of an Email Centered Task Tool. In: Proceedings of the SIGCHI Conference. ACM Press, New York (2003)

Blum, A.F.: Theorizing: On the Beginning of Social Inquiry. Routledge and Kegan Paul, London (1974)

Chudoba, K., Wynn, E., Lu, M., Watson-Manheim, M.B.: How Virtual Are We? Measuring Virtuality in a Global Organization. Information Systems J. 15(4), 279-306 (2005)

Csikszentmihalyi, M.: Flow and the Psychology of Discovery and Invention. Harper Perennial, New York (1997)

Cummings, J.M., Espinosa, J.A., Pickering, C.: Crossing Spatial and Temporal Boundaries in Globally Distributed Projects: A Relational Model of Coordination Delay. Information Systems Research 20(3), 420-439 (2009)

Dreyfus, H.L.: What Computers Can't Do: The Limits of Artificial Intelligence. Harper \& Row, New York (1978)

Escobar, A.: Encountering Development: The Making and Unmaking of the Third World. Princeton University Press, Princeton (1995)

Foucault, M.: The Archaeology of Knowledge and the Discourse on Language. Tavistock Publications, London (1972)

Hammer, M., Champy, J.: Reengineering the Corporation. Harper Collins, New York (2001)

Jensen, C., Lonsdale, H., Wynn, E.: The Life and Times of Files and Information: A Study of Desktop Provenance. In: Proceedings of Computer-Human Interaction: 28th ACM Conference on Human Factors in Computing Systems. ACM Press, New York (2010) 
Knorr-Cetina, K.: Epistemic Cultures: How the Sciences Make Knowledge. Harvard University Press, Cambridge (1999)

Latour, B.: We Have Never Been Modern. Harvard University Press, Cambridge (1993)

Latour, B.: Pandora's Hope: Essays on the Reality of Science Studies. Harvard University Press, Cambridge (1999)

Light, J., Miller, J.D.: Miramar: A 3D Workplace. In: Proceedings of IPCC, IEEE Professional Communication Conference (2002)

Lu, M., Wynn, E., Chudoba, K., Watson-Manheim, M.B.: Understanding Virtuality in a Global Organization: Toward a Virtuality Index. In: Proceedings of the International Conference on Information Systems (2003)

Reeves, B., Nass, C.: The Media Equation: How People Treat Computers, Television and New Media Like Real People and Places. University of Chicago Press, Chicago (2002)

Stumpf, S., Rajaram, V., Li, L., Burnett, B., Wong, W.-K., Dietterich, T., Sullivan, E., Drummond, R., Herlocker, J.: Interacting Meaningfully with Machine Learning Systems: Three Experiments. International J. of Human-Computer Studies 67(8), 639-662 (2009)

Tesler, L.: The Smalltalk Environment. Byte 6(8), 90-147 (1981)

Watson-Manheim, M.B., Crowston, K., Chudoba, K.M.: A New Perspective on Virtual: Analyzing Discontinuities in Work Environments: In: Proceedings of HICSS (2002)

Zimmerman, M.E.: Heidegger's Confrontation with Modernity: Technology, Politics, and Art. Indiana Series in the Philosophy of Technology, Bloomington (1990)

Zuboff, S.: In the Age of the Smart Machine: The Future of Work and Power. Basic Books, New York (1984)

\section{About the Author}

Eleanor Wynn holds a Ph.D. in Linguistic Anthropology from the University of California at Berkeley. Her dissertation research at Xerox Palo Alto Research Center was the first anthropological study of office work in the computer era, using conversation analysis to show cognitive and social processes embedded in group knowledge. She has worked as a researcher senior scientist at Xerox and Bell-Northern and as a Principal Engineer at Intel Corporation, as well as consulting on workforce information system requirements to other large companies. Her academic work includes visiting teaching engagements, scholarly publications, and service as conference chair. Dr. Wynn's current research interest is in organizations as complex systems and the application of complexity modeling methods to enterprise processes at all scales. 